\title{
Electrical Stimulation of the Human Visual Cortex
}

\author{
Preliminary Report
}

\author{
ANDREW TALALLA, LEO BULLARA and ROBERT PUDENZ
}

SUMMARY: A feasibility study for the development of a human visual prosthe sis has led several workers to observe the effects of electrical stimulation of the human visual cortex. Experience with such stimulations of three normalsighted patients is reported. The results confirm some of the findings of other workers, but do not show that multiple phosphenes were experienced by our patients, using strictly limited parameters of stimulation.

RESUME: Une étude pratique sur le développement d'une prothèse visuelle humaine a amené plusieurs chercheurs à observer les effets de la stimulation électrique du cortex visuel chez l'humain. L'expérience de ces stimulations sur 3 patients normaux est rapportée. Les résultats confirment quelques unes des découvertes d'autres chercheurs, mais n'indiquent pas que plusieurs phosphènes ont été ressentis par nos patients, utilisant strictement des paramètres limités de stimulation.
Although the concept of electrical stimulation of the human visual system has long been proposed as an aid to the blind, it was the work of Brindley and Lewin (1968) that kindled the current interest in an electronic prosthesis. We have noted the effects of electrical stimulation of the visual area of three normalsighted patients. This brief report attempts to confirm and extend the work of Brindley and Lewin. Their observations are important both for an understanding of the physiological mechanisms involved in the visual cortex and for the possibility of devising a useful visual prosthesis for the blind.

Arrays of 18 platinum electrodes embedded in silastic sheets were placed on the calcarine cortex and occipital pole respectively of three normal-sighted patients undergoing occipital craniotomy for other reasons. In two patients arrays were placed on the inferior calcarine convolution, and on the superior convolution of the third patient while all three had the second array placed on the occipital pole (Figs. 1 and 2). Selective stimulation of the electrodes was performed on the first, second and third post-operative days.

Parameters of Stimulation. Stimulus modes and parameters were restricted on the basis of data obtained from the effect of current density on the blood-brain-barrier (Talalla and Pudenz, 1973). (Table I).

Position of Phosphenes. These were plotted in two planes along Bjerrum co-ordinates in a bowl perimeter. In all three patients
From the University of Southern California School of Medicine, Los Angeles and the Huntington Institute of Applied Medical Research, Pasadena, California.

Reprint address: Dr. Andrew Talalla, Clinical Neurosciences, McMaster University, 1200 Main St. West, Hamilton, Ontario L8S 4J9

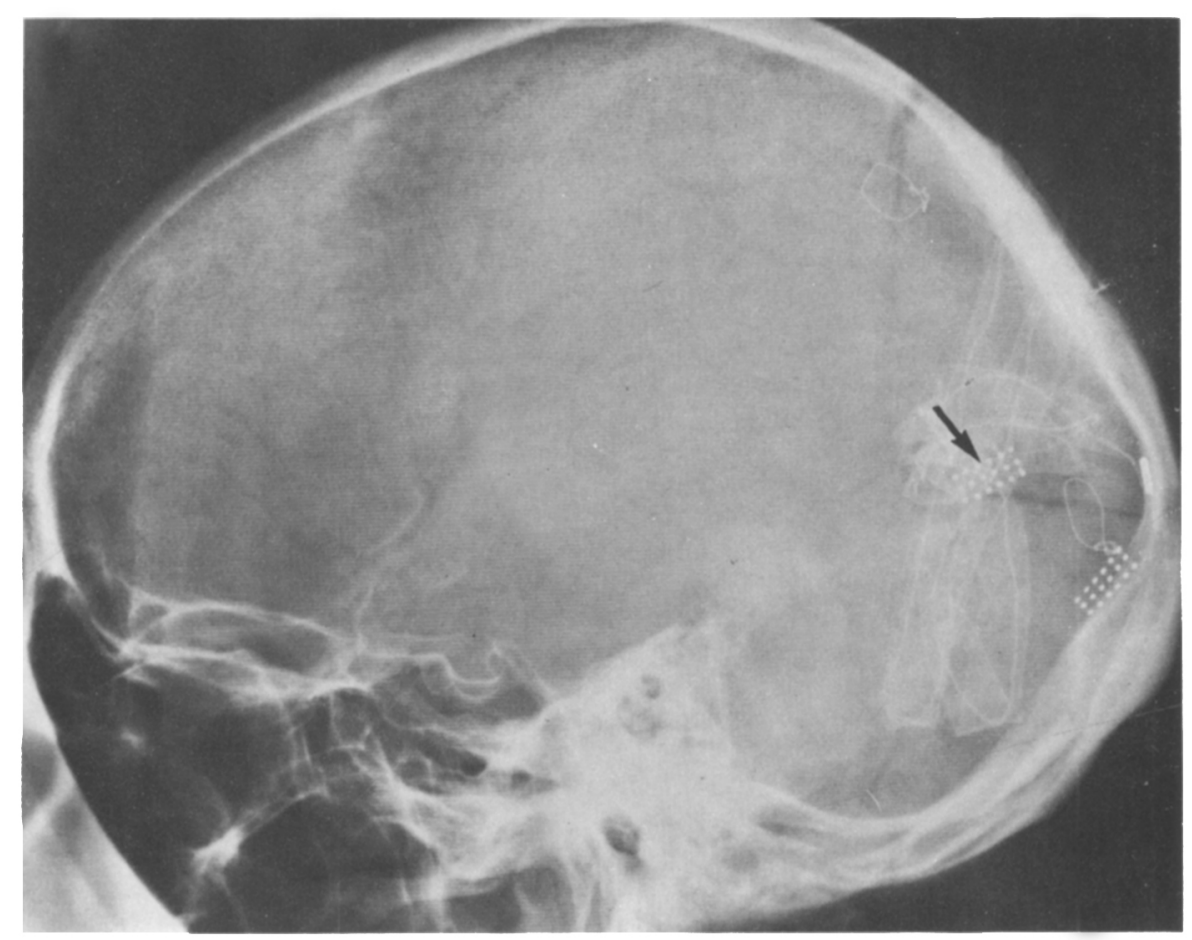




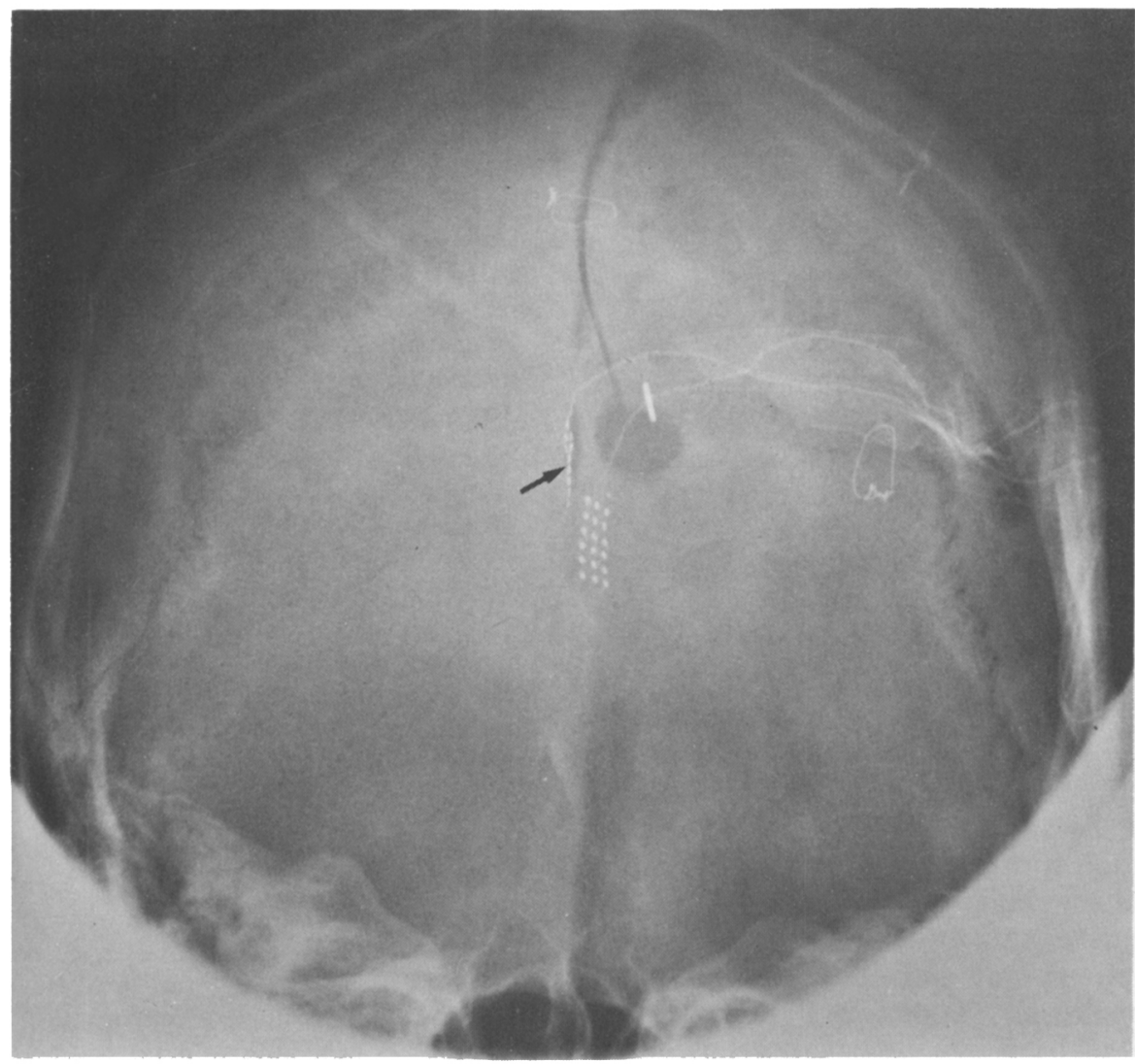

Figures $l$ and 2-Post-operative skull $\mathrm{x}$-rays showing position of calcarine array (arrowed) and occipital polar array of 18 electrodes each.

\section{TABLE 1}

Stimulus modes and parameters used on the three patients.

Electrode diameter:

1 millimeter

Electrode configuration: monopolar

Current Wave form: Biphasic capacitativelycoupled

Current amplitude:

Pulse duration: $0.75 \mathrm{~mA}-3 \mathrm{~mA}$

$0.5 \mathrm{msec}$.

$50 \mathrm{pps}$

3 seconds stimulation of the occipital pole confirmed the original observation of Otfrid Foster's patient (1929) of a phosphene in the center of the field of vision. Stimulation of the calcarine convolution resulted in phosphenes in the appropriate quadrant of the opposite visual field. All phosphenes were described as being approximately $15 \mathrm{~cm}$. from the patient,

Shape of Phosphenes. With the exception of one patient who reported streaks of light, all other phosphenes were reported as circular - "about the size of a quarter." One patient reported a cluster of small spots of light which together made a single quarter-sized phosphene. This patient also described haloes around his phosphenes.

Color of Phosphenes. Unlike Brindley's patient, all our patients reported colored phosphenes. There was no correlation between the red, yellows, blues, greens and whites with any single parameter of stimulation.

Patterns of Phosphenes. Despite having the majority of the 36 electrodes able to evoke phosphenes resimultaneous or sequential stimulation of these electrodes to produce convincingly more than one phosphene at a time. We were therefore unable to evoke even the simplest of patterns as described by Brindley's patient and also reported by Dobelle et al (1974).

Movements of Phosphenes. Phosphenes moved with eye movements. peatedly, we were unable with
For purposes of plotting the position of phosphenes, the patients were made to fixate on a small target light at the base of a bore-sight in the center of the bowl perimeter. When asked to alter their gaze the patients always reported that the phosphenes moved with the visual axis. The reported streaks of light in the one patient could always be anticipated, for upon each successful stimulation his eyes were observed to move before the reported streak. There is, in the instance of this patient and in other reports of streak phosphenes, (Chapanis, Walker and Uematsu, 1973) the likelihood of the patient attempting to track his phosphenes.

Reproducibility of Phosphenes. When electrodes which were known to evoke phosphenes were repeatedly stimulated, phosphenes were reported in the same position. We were unable to evoke two such phosphenes simultaneously, even with electrodes known to produce widely separated images. Sequential stimulation of such electrodes also failed to evoke more than one phosphene at a time.

Persistence of Phosphenes. Phosphenes reported by two patients were short-lived, barely longer than the stimulus time. In the third patient, despite stimulation times of less than three seconds, phosphenes were reported as lasting unchanged for six minutes. This patient was subjected to sequential stimulation of electrodes known to evoke phosphenes. Although we were unable to produce more than one simultaneous phosphene, the patient repeatedly observed that with the sequential stimulation of phosphene-yielding electrodes, a persistent phosphene would always be abolished if a brighter phosphene was experienced, even if this second phosphene was at a distance. The persistent phosphenes of this third patient would always be dismissed with the switching on of lights in the previously darkened room in which all the patients were studied.

We have thus confirmed much data reported by Brindley and Lewin but significantly we were unable to produce more than one phosphene 
simultaneously. Our patients reported phosphenes in several colors, some with multi-colored haloes. One patient experienced persistence of his phosphenes for several minutes and these persistent phosphenes were repeatedly suppressed by rival brightness.

\section{REFERENCES}

BRINDLEY, G. S., and LEWIN, W. S. (1968). The Sensations Produced by Elec- trical Stimulation of the Visual Cortex. Journal of Physiology, 196, 479-793.

CHAPANIS, N. P., UEMATSU, S., KONIGSMARK, B. et al. (1973). Central Phosphenes in Man: a report of three cases. Neuropsychologia, II, 1-19.

DOBELlE, W. H., MLADEJOVSKY, M. G., and GIRVIN, J. P. (1974). Artificial Vision for the Blind: Electrical Stimulation of Visual Cortex Offers Hope for a Functional Prosthesis. Science, 183, 440-444.
FOERSTER, O. (1929). Beitrage zur Pathophysiologie der Schbahn und der Schshore. Journal of Psychology and Neurology, Lpz., 39, 463-485.

TALALlA, A., PUDENZ, R. H., and BULLARA, L. (1973). The Effect of Current Density on the Brain and its Microcirculation. Presented at the 5th International Congress of Neurological Surgery, Tokyo, Japan. 